\title{
A intervenção positiva do Estado no domínio econômico por meio da forma cooperativa
}

\author{
The positive intervention of the State in the economic domain \\ through the cooperative form
}

Marco Aurélio Bellato Kaluf1

I.Coop-Faculdade do Cooperativismo (Brasil)

doi: http://dx.doi.org/10.18543/dec-17-2021pp151-169

Recibido: 15.02.2021

Aceptado: 25.03.2021

Sumário: 1. Considerações iniciais. 2. A Política Nacional de Cooperativismo (Brasil) como intervenção positiva do Estado. 3. Supremacia do interesse público e a harmonização dos direitos fundamentais. 4. O Princípio da Democracia Econômica, Social e Cultural em comunhão com a cooperação e coesão social. 5. A inteligência econômica do 'estado de cooperação' e 'lucro' cooperativo. 6. Considerações finais. Referências.

Resumo: Este artigo propõe que a forma econômica cooperativa, no Brasil, seja um meio determinado pela Constituição Federal para que o Estado promova o equilibro socioeconômico. A intervenção estatal não pode se limitar a neutralizar falhas de mercado, mas pelo contrário, por ordem constitucional, é determinado ao Estado o dever de apoio e estímulo à forma econômica cooperativa para proporcionar mais uma ferramenta aos cidadãos para partici-

1 Professor de Direito Cooperativo e coordenador da pós-graduação de Direito Cooperativo no Instituto do Cooperativismo I.Coop - Faculdade do Cooperativismo. Assessor jurídico de cooperativas, atuante na área consultiva. Foi Assessor Jurídico da OCB (Organização das Cooperativas Brasileiras), do Sescoop (Serviço Nacional de Aprendizagem do Cooperativismo), da Confederação Sicoob Brasil (Confederação Nacional das Cooperativas do Sicoob e também da Sicoob Central São Paulo (Cocecrer/SP). Graduado em Direito pela Faculdade de Direito da Pontifícia Universidade Católica de São Paulo (PUC/SP), MBA em Cooperativismo pela FEA/USP. Foi professor de Direito de Empresas e Financeiro na FGV/RJ, de Direito no MBA da Fundace/Faculdade de Economia e Administração da USP Ribeirão Preto, professor convidado para cursos de pós-graduação da Fundação Pedro Leopoldo (MG), professor conteudista para UnisulVirtual, campus de educação a distância da Universidade do Sul de Santa Catarina, e Diretor do Instituto Brasileiro de Estudos e Pesquisa Ambientais e Cooperativos-lbpeac. Palestrante em Seminários e Congressos de Direito Empresarial, Ambiental, Societário, Direito Financeiro e Cooperativo. Co-autor das obras 'Aspectos Jurídicos das Cooperativas de Crédito' e 'Sustentabilidade e Cooperativismo - Uma Filosofia para o Amanhã'. Endereço eletrônico: marco@bellatokaluf.com. 
par da livre concorrência. Dessa maneira, garante-se, como direito fundamental, que o cidadão tenha a possibilidade de se livrar da hipossuficiência e passar a ser agente no âmbito da livre concorrência, assim também atuando para a obtenção do bem-estar social comum.

Palavras-chave: Forma econômica cooperativa. Equilíbrio socioeconômico. Dever do Estado. Interesse Público. Livre concorrência.

Abstract: This article proposes that the cooperative economic form, in Brazil, is a means determined by the Federal Constitution for the State to promote socioeconomic balance. State intervention cannot be limited to neutralizing market failures, but on the contrary, by constitutional order, the State is given the duty to support and encourage the cooperative economic form to provide yet another tool for citizens to participate in free competition. In this way, it is guaranteed, as a fundamental right, that the citizen has the possibility to get rid of hyposufficiency and become an agent within the scope of free competition, thus also acting for the achievement of the common social wellbeing.

Keywords: Cooperative economic form. Socioeconomic balance. Duty of the State. Public interest. Free competition. 
O bem comum pressupõe o respeito pela pessoa humana enquanto tal, com direitos fundamentais e inalienáveis orientados para o seu desenvolvimento integral. Exige também os dispositivos de bem-estar e segurança social e o desenvolvimento de vários grupos intermédios, aplicando o princípio da subsidiariedade. Entre tais grupos, destaca-se de forma especial a família, enquanto célula basilar da sociedade. Por fim, o bem comum requer a paz social, isto é, a estabilidade e a segurança de certa ordem, que não se realiza sem uma atenção particular à justiça distributiva, cuja violação gera sempre violência. Toda a sociedade —e nela especialmente o Estado- tem obrigação de defender e promover o bem comum.

Papa Francisco ${ }^{2}$

\section{Considerações iniciais}

Tema que nos parece bastante intrigante é a participação dos particulares, cidadãos integrantes do Povo de uma nação, na regulação dos mercados, ou seja, no equilíbrio da ordem econômica da nação.

Nessa perspectiva, não há como deixar de se pensar em como o Estado, por meio da positivação de normas, pode incentivar tais mecanismos para garantir a esses particulares (players) a atuação no mercado sem a necessidade de proteção e tratamento como hipossuficientes.

Além disso, existem outros agentes que são as corporações e empresas de maior, quanto às quais os Estados, comumente, preferem a fiscalização por meio de agências.

Essa lógica, com base nas premissas de proteção ao hipossuficiente e fiscalização do agente de maior porte, leva à uma dicotomia onerosa tanto ao Estado como aos particulares.

Em nossa visão, uma estrutura que perde eficiência por manter centralizada no Estado tanto a proteção aos agentes de menor dimensão como a fiscalização dos de maior porte. Isso gera uma falta de eficiência econômica para o país.

A eficiência da ordem econômica é a premissa de desenvolvidos como progresso de uma nação, aliás, na bandeira brasileira essas duas palavras se destacam: ordem e progresso.

Não há desenvolvimento sem progresso e a estrutura baseada na dicotomia de proteção do menor e fiscalização do maior é fadada à

2 Carta Encíclica do Papa Francisco, qual seja, Laudato Si': Sobre o Cuidado da casa Comum. Libreria Vaticana. Editoras Paulinas, 2. ${ }^{a}$ reimpressão, São Paulo: 2015, página 128. 
ineficiência quanto ao equilíbrio da ordem econômica e o bem-estar dos cidadãos.

E nesse sentido, Caliendo (2009) 3 bem explica isso a questão de eficiência da ordem econômica no sentido do bem-estar do cidadão:

A eficiência econômica irá possuir o sentido de maximização de determinados bens sociais eleitos como sendo de significativa importância. Como podemos notar, não se trata de um conceito neutro ou ausente de compreensões ou pré-compreensões, visto que a determinação de determinados objetivo a ser maximizado expõe uma visão de mundo. Será fundamental a definição de «unidade de medida» (measuring rod, sendo que a rod significa em inglês bastão ou vara) do critério da eficiência. Estes dois critérios tentam responder ao questionamento: se as pessoas maximizam o que elas maximizam? (If people maximiza, what they maximize?). Os bens a serem escolhidos são: i) utilidade (utility), ii) dinheiro (money), iii) «riqueza humana e iv) felicidade (happiness). (Destacou-se)

Enfim, problema enfrentado no presente artigo constitui-se na indagação: o Estado maximiza seus recursos por meio da positivação de normas de liberdade para a associação sob a forma econômica cooperativa?

O mais comum é que os Estados (países), por meio de suas normas positivadas, prevejam dispositivos jurídicos de proteção aos consumidores e regulação dos mercados para impedir práticas nocivas e abusivas, as quais ferem o bem-estar social, contudo, sempre no sentido de se restringir a liberdade econômica. Logo, mantém-se um controle e fiscalização para intervenções na ordem econômica e, quanto a isso não discordamos, mas indagamos se há a liberdade para os cidadãos se mobilizarem de maneira que avancem para não serem hipossuficientes e, assim, possam exercer plenamente a livre concorrência.

Forgioni (2006), bem avalia a questão da intervenção estatal para correção de falhas de mercado, no entanto, dentro de um campo claro e delimitado que é a neutralização de falhas de mercado. Explica Paula Forgioni4:

Para a maioria dos autores ligados à $A E D$, na presença de falhas de mercado, justifica-se a intervenção com o escopo específico de supri-las ou de neutralizá-las. O objetivo da atuação estatal é, assim, claro e delimitado: eliminar [ou reduzir] essas falhas,

3 Direito Tributário e Análise Econômica do Direito: uma visão crítica. Rio de Janeiro: Elsevier, 2009, p. 71.

4 Análise econômica do direito: paranóia ou mistificação? Revista do Tribunal Regional Federal 3 - RTRF3R n. ${ }^{\circ} 77$, págs. 35/61. 
para que se tenha como resultado o melhor grau de eficiência alocativa possivel, ou seja, logre-se obter um ambiente econômico como se falhas não houvesse. Em outras palavras, a neutralização das falhas que se dá pela intervenção visa apenas a simular o funcionamento de um mercado concorrencial. (Destacou-se)

Na correção de falhas de mercado é aceitável a intervenção estatal, mas também pode o Estado agir ao contrário, como no caso da forma econômica cooperativa, gerando e garantindo a liberdade de ação para a livre concorrência cumulada com o apoio e estímulo, ou seja, uma intervenção positiva.

Trata-se de mais uma ferramenta disponibilizada aos cidadãos, aonde passam a ser atuantes na livre concorrência, bastante se unirem em estado de cooperação e se constituírem formalmente em uma sociedade cooperativa.

Observa-se que os Estados buscam manter o equilíbrio econômico e, assim o bem-estar social nessa dicotomia proteção e fiscalização, mas até que ponto pode o cidadão não ser dependente da ação estatal para correção de falhas de mercado para seu bem-estar?

E no Brasil não é diferente. A própria 'lei das leis', ou seja, a Constituição Federal de 1988 (CF), chamada de Constituição Cidadã ${ }^{5}$, determina quanto aos agentes de mercado que haverá uma regulação para os de maior porte e a proteção para os de menor dimensão. Nessa tônica de atuação do Estado no mercado e concorrência, define o artigo 170 da CF brasileira:

Art. 170. A ordem econômica, fundada na valorização do trabalho humano e na livre iniciativa, tem por fim assegurar a todos existência digna, conforme os ditames da justiça social, observados os seguintes princípios:

I. soberania nacional;

II. propriedade privada;

5 Esse termo foi utilizado na promulgação do texto da Assembleia Constituinte de 1988: 'o então presidente da Câmara dos Deputados, Ulysses Guimarães, declarou em 27 de julho de 1988 (foto) a entrada em vigor da nova Constituição Federal - apropriadamente batizada de Constituição Cidadã porque era o Brasil, nessa época, um país recém-saído da ditadura militar na qual os princípios constitucionais foram trocados por porões de tortura dos oponentes políticos do militarismo. Um ano e meio após a sua formação, a Assembleia Nacional Constituinte, composta por 487 deputados e 72 senadores, chegava a um consenso sobre as normas jurídicas'. Fonte: Revista IstoÉ, sítio eletrônico (https://istoe.com.br/161883_A+CONSTITUICAO+CIDADA ). Consulta em 20 de outubro de 2020 . 
III. função social da propriedade;

IV. livre concorrência;

V. defesa do consumidor;

VI. defesa do meio ambiente, inclusive mediante tratamento diferenciado conforme o impacto ambiental dos produtos e serviços e de seus processos de elaboração e prestação. (Redação dada pela Emenda Constitucional $n .{ }^{\circ} 42$, de 19.12.2003)

VII. redução das desigualdades regionais e sociais;

VIII. busca do pleno emprego;

IX. tratamento favorecido para as empresas de pequeno porte constituídas sob as leis brasileiras e que tenham sua sede e administração no País. (Redação dada pela Emenda Constitucional n. ${ }^{\circ} 6$, de 1995)

Parágrafo único. É assegurado a todos o livre exercício de qualquer atividade econômica, independentemente de autorização de órgãos públicos, salvo nos casos previstos em lei. (Destacou-se)

Mas em contraponto à total proteção e regulação, advinda somente pela estrutura do Estado, designou-se também na CF de 1988, o interesse público com a participação dos particulares, e isso é a ordem do artigo constitucional 174:

Art. 174. Como agente normativo e regulador da atividade econômica, o Estado exercerá, na forma da lei, as funções de fiscalização, incentivo e planejamento, sendo este determinante para o setor público e indicativo para o setor privado. (Vide Lei n. ${ }^{\circ}$ 13.874, de 2019)

$\S 1 .{ }^{\circ}$ A lei estabelecerá as diretrizes e bases do planejamento do desenvolvimento nacional equilibrado, o qual incorporará e compatibilizará os planos nacionais e regionais de desenvolvimento.

$\S 2 .^{\circ}$ A lei apoiará e estimulará o cooperativismo e outras formas de associativismo. (Destacou-se)

Note-se que a ação, o equilíbrio e o progresso da ordem econômica, pauta-se também na atitude indicada pelo texto constitucional (caput do artigo 174) e, quanto a isso, é acrescido que a forma econômica cooperativa será apoiada e estimulada.

Dessa maneira, a CF de 1988 abraça o matiz da livre concorrência pelos agentes hipossuficientes, quando determina o apoio e estímulo ao cooperativismo, 'na forma' da lei. 
E a lei a que se remete a CF de 1988 é a Lei n. ${ }^{\circ}$ 5.764/1971, que aqui denominaremos simplesmente por Lei Coop ${ }^{6}$, sendo que nela não se trata somente da constituição de sociedades cooperativas, mas sim se determina a constituição de uma Política Nacional do Cooperativismo. Veja-se a ementa da Lei Coop:

Define a Política Nacional de Cooperativismo, institui o regime jurídico das sociedades cooperativas, e dá outras providências. (Destacou-se)

E dessa forma, o Brasil, efetivamente, assume uma Política Nacional de Cooperativismo como função de Estado e, portanto, ao nosso ver como uma intervenção estatal positiva no domínio e ordem econômica nacional.

\section{A Política Nacional de Cooperativismo (Brasil) como intervenção positiva do Estado}

A concatenação e lógica trazida pela Carta Magna brasileira, efetivamente, traz à baila a ação dos particulares no sentido de poder atuar em prol da eficiência econômica, não somente que lhes é própria, mas também na qual está inserido, qual seja a ordem econômica nacional.

Mais ainda, a CF de 1988 coloca a pedra fundamental para a possibilidade dessa ação privada na ordem econômica como direito fundamental, conforme definido no artigo $5^{\circ}$, inciso XXVIII, ora cláusula pétrea?:

XVIII - a criação de associações e, na forma da lei, a de cooperativas independem de autorização, sendo vedada a interferência estatal em seu funcionamento; (Destacou-se)

6 Aqui utilizamos o termo 'Coop' para que seja possível a mais fácil e ágil a cognição e percepção dos princípios e valores inerentes ao Cooperativismo. O termo, aliás, é o termo utilizado pela Aliança Cooperativa Internacional $(\mathrm{ACl})$ e, no Brasil, representado o movimento 'Somos Coop'. E como breve descrição do movimento Somos Coop, vale transcrever a descrição trazida pelo sítio de internet www.somos.coop.br: 'Somos um modelo de negócio diferenciado, onde pessoas juntas, em torno de um mesmo objetivo, criam impactos positivos para o país inteiro'. Consulta em 20 de outubro de 2020.

7 Cláusula pétrea é aquela que não pode ser alterada por emenda à Constituição Federal. Tal determinação encontra-se no artigo Art. 60. A Constituição poderá ser emendada mediante proposta: [...] 4 . $^{\circ}$ Não será objeto de deliberação a proposta de emenda tendente a abolir: [...] IV - os direitos e garantias individuais. 
A norma em questão (inciso XXVIII do artigo $5 .^{\circ}$ da CF), a princípio, pode ser entendida até mesmo como impossibilidade do que defendemos ser uma intervenção estatal pró (positiva) cooperativas, pois veda tal atitude do Estado. Entretanto, sem grandes digressões, claro é que a CF de 1988 proíbe a intervenção quanto à autorização para se constituir uma cooperativa bem como para desestimular ou impedir a atitude da cooperação.

Simples é a verificação dessa assertiva quando se promove a hermenêutica sistêmica do texto constitucional, ora comungada essa disposição do inciso XVIII do artigo $5 .^{\circ}$, com a disposição do $\S 2 .^{\circ}$ do artigo 174.

Logo, iniludível que a CF de 1988 determina ao Estado que cumpra uma política de apoio e estímulo para agentes (players) formados por hipossuficientes, ou seja, cooperativas. Essa união de pessoas sob a forma econômica cooperativa faz com que existam novos agentes mais potentes e que terão maior poder de negociação e barganha frente a corporações e grandes empresas.

Tal player de mercado passa a interagir com valores e princípios que the são próprios sem se tornar refém de corporações ou grandes empresas, passando a exercer, mais ainda, a livre concorrência, contribuindo para o equilíbrio da ordem econômica.

E esse plano de apoio e estímulo prescrito pelo $\S 2 .^{\circ}$ do artigo 174, da CF, advém de um anseio antigo do Estado Brasileiro, que cuja menção já era feita na própria exposição de motivos da Lei Coop:

A preocupação governamental de dispensar o necessário apoio às atividades cooperativistas, ressalta do programa de «METAS $E$ BASES PARA A AÇÃO DO GOVERNO», onde figura promessa de 'concessão de estímulos especiais ao COOPERATIVISMO». (Destacou-se)

Dessa forma, a conclusão factível que o Estado Brasileiro, na forma do artigo 170 (caput), da CF de 1988, fica vinculado ao apoio e estímulo à forma econômica cooperativa, inclusive quanto ao 'incentivo e planejamento' e isso via lei própria, atualmente a Lei Coop (5.764/1971). 


\section{Supremacia do interesse público e a harmonização dos direitos fundamentais}

Nesse contexto em que há uma Política Nacional de Cooperativismo, também é importante destacar que não há conflito entre o interesse público e os direitos fundamentais.

Ao contrário, o que existe com a lógica constitucional brasileira é a determinação para que o interesse público se volte e perceba, a vantagem da cooperação de que seja mantido o equilíbrio socioeconômico.

No entanto, a averiguação do impacto socioeconômico somente poderá ser avaliada após monitoramento ${ }^{8}$, ou seja, em seguida à constituição de sociedades cooperativas e aferição de seus resultados.

Não há como afirmar que a forma econômica cooperativa será perenemente garantidora do bem-estar social e equilíbrio econômico, mas se tem o direcionamento de que há uma política nacional que determina a estimular e apoiar, tal modelo.

Certo é que a forma cooperativa, baseada no conhecimento dos sócios quanto à comunidade em que vivem, que se configura um princípio, tal como liberdade de ingresso e saída da sociedade, ora outra princípio Coop, dentre outros mais 5 princípios determinados universais pela Aliança Cooperativa Internacional-ACl, há a probabilidade maior de se efetivar o reconhecimento das vantagens socioeconômicas.

Uma determinada coletividade que constitui um agente econômico sob a forma cooperativa, cria uma verdadeira consciência coletiva inclinada não somente a buscar o interesse pessoal de cada indivíduo, mas sim de reconhecer que em grupo, ou seja, em cooperação, cada componente terá a garantia de ser beneficiado pelo resultado do grupo. Logo, cada novo agente formado pelos individuais, ou seja, cada nova cooperativa, já é elemento maior do que se tem como interesse público.

Nesse sentido, a lógica da hermenêutica sistemática entre o artigo 170 , artigo $174, \S 2 .^{\circ}$ e o inciso XXVIII, do artigo $5 .^{\circ}$, da CF de 1988 , demonstra a compatibilidade de que, ao mesmo tempo que a Carta Maior tem interesse público em estimular e apoiar o Cooperati-

8 No Brasil existe o Serviço Nacional de Aprendizagem do Cooperativismo (Sescoop), criado por meio da Medida Provisória (MP) 1.715 de 1998, cujo um dos objetivos é o monitoramento das cooperativas. Mas é importante destacar que tal entidade monitora para ter subsídios que possibilitem outro objetivo que detém, qual seja, a Educação, que é um matiz importante para se garantir a governança com o espírito e princípios do Cooperativismo. 
vismo, assim o faz, porque garante o direito fundamental de cada indivíduo e vice-versa.

Portanto, neste caso, a supremacia do interesse público comunga com o interesse privado, pois a cooperação faz com que as pessoas se unam sob a forma econômica cooperativa, promovam um resultado e impacto socioeconômico mais equilibrado.

Pinheiro e Sadi (2005), bem ilustram a questão da cooperação por meio da análise econômica do direito (AED) e a remissão à Teoria dos Jogos e do Equilíbrio de John Nash ${ }^{9}$. Os autores explicam que a economia, pelo menos até Nash, nunca se importou em relação 'a cada jogador' (agente no mercado), pois, em se mantendo somente a livre iniciativa, o equilíbrio socioeconômico seria garantido, tal como no modelo descrito por Adam Smith.

No entanto, trazem uma abordagem de que a cooperação foi entendida pela economia, como de maior eficácia quanto aos efeitos socioeconômicos. Para tanto fazem citação a Duílio de Ávila Bêrni10:

O conceito de Nash põe em ação algumas das mais formidáveis características humanas: cada um deseja o melhor para si próprio, mas sabe que, numa interação como acima, o melhor jogador só é perene (quando a relação for de vizinhança, parentesco, trabalho) se combinar com o que outro considera como sendo o melhor para si próprio. Este tipo de raciocínio evoca a famosa frase de Adam Smith, no sentido de que o açougueiro, o cervejeiro e o padeiro preparam nosso jantar pensando no bem-estar deles, e não no nosso. Mas eles sabem que só compraremos suas carnes cervejas e pães caso seu produto nos propicie bem-estar. Sabemos que eles fazem o melhor possível para nós, a fim de voltemos a comprar deles, ou digamos a terceiros que lá comprem. (Destacou-se)

E quanto a essa compatibilidade, Di Pietro (2006) é enfática em avaliar que a interpretação do que é indeterminado na supremacia do interesse público, deve ser cumulada da razoabilidade e a legalidade:

'O princípio da supremacia do interesse público convive com os direitos fundamentais do homem e não os coloca em risco. Ele encontra fundamento em inúmeros dispositivos da Constituição e tem que ser aplicado em consonância com outros princípios consagrados no ordenamento jurídico brasileiro, em especial com obser-

9 Direito, economia e mercados, Rio de Janeiro, Elsevier, 2005, 2. ${ }^{a}$ reimpressão, p. 179.

10 Teoria do Jogos, São Paulo, Reichmann \& Affonso Editores, p. 27. 
vância do princípio da legalidade. A exigência de razoabilidade na interpretação do princípio da supremacia do interesse público se faz presente na aplicação de qualquer conceito jurídico indeterminado; atua como método de interpretação do princípio (na medida que permite a ponderação entre o interesse individual e o público) e não como seu substituto.'

No caso da forma econômica cooperativa, tanto há a legalidade, desde a CF de 1988 até a Lei Coop, como há a razoabilidade em se verificar que, por meio da cooperação, a eficácia do fim público é maximizada.

Em suma, pelo ordenamento jurídico brasileiro, quanto mais o Estado apoiar e estimular o desenvolvimento da forma econômica cooperativa, mais eficiência terá em relação ao equilíbrio socioeconômico.

Mais ainda, estará atendendo ao anseio da liberdade e garantia fundamental dos seus cidadãos, permitindo que sejam agentes (players) de mercado quando unidos sob a forma econômica cooperativa. Isso garante a livre iniciativa e ainda gera aumento do número de players de mercado, o que implica em crescimento da concorrência e assim mantém o equilíbrio econômico.

\section{O Princípio da Democracia Econômica, Social e Cultural em comunhão com a cooperação e coesão social}

Muito comum, é que a utilização da forma econômica cooperativa se dê por verdadeiros vazios da atuação estatal. São incontáveis os casos em que os particulares, muitas vezes, não servidos dos serviços essenciais pelo Estado, se unam em cooperação para tê-los (serviços públicos).

Nesse espectro, importante é lição de Canotillo quando vislumbra o Princípio da Democracia Econômica, Social e Cultural ${ }^{11}$ :

O princípio da democracia económica, social e cultural é relevante ainda como 'princípio organizatório da prossecução de tarefas' pelos poderes públicos. A administração pública é uma administração 'socialmente vinculada' à estruturação de serviços fornecedores de prestações sociais (ensino, saúde, segurança social). Esta vinculação social não proíbe que essas prestações sejam assegura-

11 Direito Constitucional e Teoria da Constituição, Almedina, Coimbra, 1997, p. 344. 
das por 'esquemas organizatórios jurídico-privados' ou por entidades autónomas'.

[...]

Mas há um limite imposto pelo princípio da democracia económica, social e cultural: o acesso aos bens públicos (ensino, saúde, energia água, comunicação, crédito) não implicar a violação do 'núcleo essencial' dos direitos sociais já efectivados. A transmutação de formas de organização públicas em esquemas organizatórios privados (ex.: telecomunicações, energia, crédito) pressupõe a continuação do princípio da universalidade de acesso aos bens indispensáveis a um mínimo de existência. (Destacou-se)

Canotilho vincula expressamente que os serviços essenciais que deveriam ser prestados pelo Estado, mesmo que servidos por 'esquemas organizatórios jurídico-privados', ainda são de interesse econômico geral, ou seja, ainda serão de interesse público.

Os serviços de interesse económico geral que passaram a ser serviços prestados por particulares ou empresas particulares, não significa que deixaram de estar vinculados aos direitos fundamentais. (Destacou-se)

A lição de Canotilho, remete a um plexo enorme de coincidências da forma cooperativa como meio de consecução de vários serviços essenciais, que o Estado deveria prover, mas, quando não conseguiu provê-los, permitiu que os indivíduos se organizassem para se auto prover dos mesmos.

Um exemplo notório, é o caso das cooperativas de eletrificação nos Estados Unidos. Com o pacote do New Deal, foi editado o Rural Electrification Act em 1936, que fomentou a distribuição de energia elétrica no país, por meio de formação de cooperativas existentes até hoje.

O modelo e a forma econômica cooperativa, a partir do Rural Electrification Act, provaram-se eficazes fazendo as vezes do Estado.

As comunidades em que foram constituídas cooperativas de eletrificação, àquela época de eletrificação rural, puderam opinar e gerir integral e democraticamente as necessidades e anseios que detinham.

Assim, se comprovou que o interesse público, foi realizado por meio da estimulação e apoio à forma cooperativa.

Tal como na visualização do equilíbrio de Nash, a análise econômica do direito (AED), corresponde à eficácia da execução dos fins públicos, ou seja, o que é interesse público.

Eficácia de uma política nacional, gera coesão social e isso é evidente na forma econômica cooperativa, pois, na integralidade, reúne 
participação cidadã, aspectos sociais, ambientais e culturais dos mais diversos, dentre tantos reconhecidos com fundamentais para a existência.

Quanto a isso, é bastante ilustrativa a definição de coesão social promovida no Rol das cooperativas como parte integrante da Economia Social na coesão social da América Latina e na Europa ${ }^{12}$.

A coesão social entendida como um processo integral que atende aos aspectos econômicos, a participação da cidadania, a igualdade de oportunidades, os aspectos culturais e baseados em valores que podem resumir-se no respeito aos direitos humanos, a transparência e a honestidade; se constitui em pré-requisito indispensável para garantir a convivência harmônica e as condições de desenvolvimento sustentável. (Destacou-se)

Como se observa, a definição de coesão social realizada pelo Rol das cooperativas como parte integrante da Economia Social na coesão social da América Latina e na Europa, ao nosso ver, é muito coincidente ao próprio preâmbulo da CF de 1988:

Nós, representantes do povo brasileiro, reunidos em Assembléia Nacional Constituinte para instituir um Estado Democrático, destinado a assegurar o exercício dos direitos sociais e individuais, a liberdade, a segurança, o bem-estar, o desenvolvimento, a igualdade e a justiça como valores supremos de uma sociedade fraterna, pluralista e sem preconceitos, fundada na harmonia social e comprometida, na ordem interna e internacional, com a solução pacífica das controvérsias, promulgamos, sob a proteção de Deus, a seguinte CONSTITUIÇÃO DA REPÚBLICA FEDERATIVA DO BRASIL. (Grifou-se)

É flagrante, que são inúmeras as interfaces que a cooperação - forma econômica cooperativa - promove em relação aos fins do Estado. São valores e princípios coincidentes e isso merecedor de bastante atenção, pois, tanto os fins de Estado como a cooperação, têm escopo legal e eficácia socioeconômica muito semelhantes.

Como coesão social, emanada da união de pessoas com base em direito fundamental constitucional, a forma econômica cooperativa é a grande possível parceira na execução dos serviços estatais tal como

12 Seminário sobre Economia Social na União Europeia e o Mercosul. Reunião Especializada de Cooperativas do Mercosul, Buenos Aires, Intercoop Editora Cooperativa Ltda., 2005, p. 211. 
propõe Rodrigues Neto (2009) em seu artigo Controle externo como instrumento de cidadania e indutor do controle social:

Defendo uma construção coletiva, tendo como parceiros o Estado e a sociedade civil, e cujo passo inicial seja a recuperação e, principalmente, a revitalização das atribuições indelegáveis do Estado. Certamente, a recuperação de valores antigos, como no caso do controle da gestão. (Destacou-se)

\section{A inteligência econômica do 'estado de cooperação' e 'lucro' cooperativo}

É nosso entendimento, que um dos pilares da forma econômica cooperativa, é o denominado estado de cooperação, conceito que desenvolvemos na obra Aspectos Jurídicos das Cooperativas de Crédito ${ }^{13}$, cujo trecho a seguir transcrevemos:

O associado cooperativista (...) não somente firma o contrato, mas sim se insere em um novo mundo, que extrapola a individualidade, e que, como um organismo vivo, depende de cada uma de suas células ou seres para continuar viva no objetivo para que foi criada, ou seja, para o fim de auxiliar seus próprios componentes.

Tal responsabilidade ocorre permanentemente em um estado contínuo denominado cooperação ('estado de cooperação'). (Grifou-se)

O estado de cooperação implica em uma perenidade de atos dos integrantes da forma econômica cooperativa, na qual mantêm a continuidade da cooperação e, assim, cada vez mais têm a visualização dos objetivos de toda a sociedade que integram.

Ao mesmo tempo em que buscam a realização de seus interesses individuais, acabam reconhecendo os interesses sociais de suas comunidades.

13 Normalmente utilizo o termo 'estado de cooperação' para delinear a contínua e permanente atitude do associado cooperativista ora praticando os atos cooperativos, dentre outras operações cooperativas (artigos 79 e seguintes da Lei 5.764/1971), junto à comunidade em que se insere a entidade cooperativa. Não se trata de ato isolado, mas sim um estado contínuo de ser, no qual se tem a atitude, o pensamento, o ato, enfim o pensamento e opção cooperativa perenemente. Primeira abordagem sobre essa expressão procedi na obra Aspectos Jurídicos das Cooperativas de Crédito, no capítulo 'A responsabilidade do associado perante a cooperativa de crédito' --- Belo Horizonte: Editora Mandamentos, 2004. 
Tal como na teoria de John Nash, acabam percebendo que por meio da cooperação as possibilidades de realização de seus interesses são maiores do que agindo individualmente frente ao mercado.

Ora caminhando em conjunto, podem até não impingir maior velocidade no seu próprio crescimento econômico, mas vão mais longe, pois constroem uma rede de interação socioeconômica voltada ao bem-estar coletiva que, por sua vez, também os abraça.

Os associados em cooperação interagem, fazem reflexões, discutem e deliberam entre si, sob a supremacia de uma assembleia geral por eles composta, ou seja, em paridade de armas e total democracia.

Assim, percebem quais são as medidas que gerarão maior eficácia para suas comunidades e, em decorrência, para si próprios. Não que deixem de realizar os interesses que detém, mas, os colocam em ordem preferencial subsidiária e decorrente do interesse coletivo.

Permanentemente, os associados ativam a forma econômica cooperativa que constituíram para realizar os interesses socioeconômicos da coletividade, os quais, em decorrência, atingirão seus próprios interesses. Isso, é o que denominamos como inteligência econômica cooperativa.

Por sua vez, da inteligência econômica cooperativa, resultam vantagens tangíveis, por exemplo, melhores preços de insumos, menores taxas, diminuiçãa de custos, dentre outros que podem ser mensurados em pecúnia, mas não constituem preço especulativo.

Além do que é tangível, essa inteligência econômica culmina em resultados intangíveis, dentre eles o bem-estar social, a diminuição de desigualdades e diferenças sociais, o desenvolvimento sustentável ${ }^{14}$, a harmonia da comunidade, maior segurança, liberdade, dentre outros aspectos que valoram tanto a cooperação, como o interesse público.

Tais resultados, tangíveis e intangíveis, podem ser entendidos como 'lucro', mas não na acepção da escola clássica de economia que se funda no padeiro, no açougueiro e no cervejeiro de Adam Smith, pois, remetem à acepção das lições que se tornaram influenciadoras da economia e do Cooperativismo, tais como Owen, que propôs um Sistema Econômico Cooperativo, além da visão de Mórus, em Utopia, King, Charles Fourier, assim como das lições da Escola Francesa de Nime com Charles Gide ${ }^{15}$, as quais buscaram modelos e técnicas econômicas contrapostas às de extrema exploração de capital vistos na Revolução Industrial.

14 Aqui se faz alusão direta ao Triple Bottom Line, tripé que conceitua a Sustentabilidade, construída pela ação econômica comungada com o interesse social e a responsabilidade ambiental.

15 Citações de Stöberl (2011). 
Uma certeza, é que a forma econômica cooperativa não busca maior especulação entre valores de produção e distribuição, em relação ao valor de venda. Como salientado, trata-se de um modelo de ação que, ademais, combate o superlucro da acepção da Escola Clássica ou do Marxismo, buscando uma equalização maior da contrapartida do esforço e valor entre as pessoas. Nessa linha, corresponde a lição de A. B. Buys de Barros (1957, p. 114):

Na teoria cooperativista, o lucro tem um sentido e uma finalidade diferentes do lucro da empresa comum. O lucro passa a ser um revenu útil à empresa para que esta seja útil igualmente à coletividade. Defende o lucro considerado remuneração do empreendedor, mas condena o superlucro provenientes de especulações ou do monopólio. (Destacou-se)

O lucro cooperativo, portanto, é o plexo de benefícios socioeconômicos que advém da forma econômica cooperativa. Por meio dele, há uma verdadeira ação moral, como ensina o Miranda (2012, p. 98 e 99), no sentido de haja um sistema de comportamento pessoal, que gera obrigações e ações aonde levam a cabo, tanto a prosperidade de sua entidade, como de toda a sociedade em geral.

Por esto, las cooperativas, después de satisfacer los interesses de sus membros, deben mirar hacia al exterior de su estrutura y buscar la forma adecuada para proover a los membros da comunidad que le rodea de las condiciones económicas, sociales y políticas, que les permitan (con sus famílias) gozar duraderamente de la igualdad de acceso a las possibilidades de expansión de su personalid. Es decir, que logren también uma transformación subjetiva, además de la económica y social.

Esta concepción de participación cooperativa, con lo local, desmuestra que la acción moral cooperativa es a la vez dinámica y humanitária.

Dentro de la comunidade, la Cooperativa no busca solo estabelecer uma estructura competitiva, de fortaleza económica, sino también aboga por la instaurácion de um orden social que, junto del económico, gire en torno de las necessidades del individuo que integra la comunidade que le rodea. (Destacou-se)

Enfim, não há um lucro especulativo materializado em moeda ou capital, e acumulado por alguns, mas sim, há um movimento econômico mensurável em um bem-estar coletivo, aonde as necessidades gerais de uma comunidade, cidade, sejam realizados. Há não uma ob- 
tenção lucrativa no sentido de capital, mas sim de sincronização das relações econômicas e sociais.

\section{Considerações finais}

Em derradeiro, retorna-se ao problema trazido nas considerações iniciais, ou seja: o Estado maximiza seus recursos por meio da positivação de normas de liberdade para a associação sob a forma econômica cooperativa?

A resposta é certa, no sentido que a positivação que garante apoio e estímulo, assim como a liberdade de constituição, da forma econômica cooperativa eleva a possibilidade dos cidadãos se tornarem menos hipossuficientes, assim como agentes mais sólidos no mercado, ademais, podendo impactá-lo de maneira a propiciar maior equilíbrio socioeconômico.

Com a positivação de uma Política Nacional de Cooperativismo, há sim, maior substrato para que a forma econômica cooperativa, possa ser utilizada como livre iniciativa e promova aumento da livre concorrência.

No entanto, cabe ir mais além da positivação ou não, de uma política cooperativista, pois o estímulo e apoio à constituição de cooperativas pode até ser promovido pelo Estado, por meio de legislação, para maximizar seus recursos e a eficiência socioeconômica, mas ainda se dependerá dos próprios indivíduos, nos seus particulares, optarem por essa liberdade econômica.

Entretanto, nossa crença é que o modelo [negocial-econômico cooperativo], que aqui denominamos forma econômica cooperativa, se desenvolva mais e que alcance maiores dimensões com substancial impacto socioeconômico, mas isso pode ser facilitado ser houver melhor compreensão da sociedade em geral, composta pelas pessoas que podem se unir em estado de cooperação e, assim, constituir agentes de mercado em cooperativos.

E nesse estado de cooperação, como arremata, Arizmendiarrieta ${ }^{16}$, os cidadãos poderão constituir uma empresa avivada para realizar seus próprios interesses além dos anseios de toda a comunidade em que vivem:

16 Fundador e dinamizador da denominada «Experiencia Cooperativa de Mondragón», cidade espanhola (País Basco), onde hoje está sediada a Mondragón Corporación Cooperativa-MCC, uma das referências mundiais do cooperativismo. ARIZMENDIARRIETA, José Maria. Pensamientos, 182. 
'empresa cooperativa es un organismo vivo; es una sociedad de personas en una comunidad, cuyo soporte es la solidaridad, y la conciencia de esta solidaridad es la fuerza impulsora en la que debemos confiar'.

Isso enfatizamos, porque o modelo é voltado para a sociedade como uma opção de agir econômico (ou melhor dizer, de inteligência econômica), cuja importância é tamanha que foi inserido na Constituição Federal e, mais ainda, como uma Política Nacional.

Cada cidadão pode buscar as ferramentas que lhe forem possíveis para alcançar seu próprio bem-estar social, mas isso não implica, necessariamente, que tenha que atuar isoladamente ou em pequenos grupos societários com o objetivo de obter a maior diferença pecuniária entre os valores dos insumos (materiais, humanos, energéticos, etc.) do precisa para vender seu próprio produto ou prestar seu serviço para os demais componentes da sociedade. Cada cidadão pode fazer uso da cooperação para vender seu produto ou prestar seu serviço, contudo, sem a necessidade de ter que especular preço de mercado ou se fazer de uma mais valia.

Nesse cenário é que se tem a prova em inúmeros países do Mundo e historicamente que a união em cooperação geral possibilidade de melhorias e conquistas econômicas sem benesses estatais.

As pessoas que se unem na forma cooperativa têm, flagrantemente, uma maior possibilidade de obtenção de um preço justo, pois não negociam valores entre si, mas sim dividem o custeio que é relativo à aquisição de um produto ou serviço. Dividem custos, na medida do que lhe é disponibilizado, assim como usufruem de uma decisão igualitária e democrática sobre todas as nuances do mercado em questão e das condições sociais que as cercam.

Logo, juntas, em cooperação, podem identificar quem são os alheios à comunidade que lhes é de interesse, e podem evitar que esses terceiros lucrem sobre elas no que precisam para manter suas condições de vida, subsistência, enfim, bem-estar social e, inclusive, com o viés econômico. Evitam o fim lucrativo desses terceiros e remetem o que não gastaram com isso para suas comunidades.

Mesmo que na busca do bem-estar individual, reconhecem que o sucesso coletivo é que lhes garante essa conquista pessoal. Dessa maneira, conclui-se em uma indagação, como não eleger uma Política Nacional de Cooperativismo para desenvolver o bem-estar social e a dignidade de um Povo? 


\section{Referências}

Cl-Aliança CoOperativa InTERnACIOnAL, disponível em: https://www.ica.coop/en. Acesso em 22/07/2020.

Arizmendiarrieta, José Maria. Pensamientos, 182.

BARros, Alamiro Bica Buys de. Instituições de Economia Política: produção, distribuição, circulação, consumo, equilíbrio econômico, flutuações cíclicas e renda nacional. Rio de Janeiro, Editor José Konfino, 2. ${ }^{a}$ edição, volume II, 1957.

BRASIL, Constituição (1988) Constituição da República Federativa do Brasil. Brasília: Senado, 1988. 168p.

BRASIL, Lei 5.764, de 16 de dezembro de 1971. Define a Política Nacional de Cooperativismo, institui o regime jurídico das sociedades cooperativas, e dá outras providências. Diário Oficial da União. Brasília, 16 dez. 1971.

CAliendo, Paulo. Direito Tributário e Análise Econômica do Direito: uma visão crítica. Rio de Janeiro: Elsevier, 2009.

Di Pietro, Maria Sylvia Zanella. Revista Interesse Público, n. ${ }^{\circ}$ 56, 2009, página 6.

FoRGIONI, Paula. Análise econômica do direito: paranóia ou mistificação? Revista do Tribunal Regional Federal 3 - RTRF3R n. ${ }^{\circ} 77$, págs. 35/61.

LeITE, Jaqueline Rosadine de Freitas; SenRA, Ricardo Belízio de Faria (Coordenadores). Aspectos Jurídicos das Cooperativas de Crédito. Editora Mandamentos: 2005, Belo Horizonte.

MIRANDA, José Eduardo de. De la crisis de identidade al rescate de la gênesis del Cooperativismo. Madrid, Editora Dykinson, 2012.

Mórus, Thomas. São Paulo: Penguin Companhia. 1. a edição, 2018.

OCB-OrganizaÇÃo dAs CoOperativas BRASILEIRAS, disponível em: https://www.ocb. coop.br. Acesso em 10/09/2020.

PINHEIRO, Armando Castelar \& SADDI, Jairo. Direito, economia e mercados, Rio de Janeiro, Elsevier, 2005, 2. ${ }^{a}$ reimpressão, p. 179.

RodRIGUes Neto, Antonio Joaquim Moraes. Controle externo como instrumento de cidadania e indutor do controle social, in Revista Interesse Público n. ${ }^{\circ}$ 56, Belo Horizonte, Editora Fórum 2009, p. 233.

Somos Coop, disponível em: https://www.somos.coop.br. Acesso em 15/07/2020. 


\section{Derechos de autor}

http://dec.revistas.deusto.es/

La revista Deusto Estudios Cooperativos es una revista de acceso abierto lo que significa que es de libre acceso en su integridad inmediatamente después de la publicación de cada número. Se permite su lectura, la búsqueda, descarga, distribución y reutilización legal en cualquier tipo de soporte sólo para fines no comerciales y según lo previsto por la ley; sin la previa autorización de la Editorial (Universidad de Deusto) o el autor, siempre que la obra original sea debidamente citada (número, año, páginas y DOI si procede) y cualquier cambio en el original esté claramente indicado.

\section{Copyright}

The Deusto Journal of Cooperative Studies is an Open Access journal which means that it is free for full and immediate access, reading, search, download, distribution, and lawful reuse in any medium only for non-commercial purposes, without prior permission from the Publisher or the author; provided the original work is properly cited and any changes to the original are clearly indicated. 